\title{
Use of the CatWalk Gait Device to Assess Differences in Locomotion between Genders in Rats Inherently and following Spinal Cord Injury
}

\author{
Jeffrey P. Datto, ${ }^{1}$ Anna K. Shah, ${ }^{1}$ Johana C. Bastidas, ${ }^{1}$ Kristopher L. Arheart, ${ }^{2}$ \\ Alexander E. Marcillo, ${ }^{1}$ W. Dalton Dietrich, ${ }^{1,3,4,5,6,7}$ and Damien D. Pearse ${ }^{1,3,6,7,8}$ \\ ${ }^{1}$ The Miami Project to Cure Paralysis, University of Miami Miller School of Medicine, Miami, FL 33136, USA \\ ${ }^{2}$ Department of Public Health Sciences, University of Miami Miller School of Medicine, Miami, FL 33136, USA \\ ${ }^{3}$ Department of Neurological Surgery, University of Miami Miller School of Medicine, Miami, FL 33136, USA \\ ${ }^{4}$ Department of Cell Biology, University of Miami Miller School of Medicine, Miami, FL 33136, USA \\ ${ }^{5}$ Department of Neurology, University of Miami Miller School of Medicine, Miami, FL 33136, USA \\ ${ }^{6}$ Neuroscience Program, University of Miami Miller School of Medicine, Miami, FL 33136, USA \\ ${ }^{7}$ Interdisciplinary Stem Cell Institute, University of Miami Miller School of Medicine, Miami, FL 33136, USA \\ ${ }^{8}$ Bruce W. Carter Department of Veterans Affairs Medical Center, Miami, FL 33136, USA
}

Correspondence should be addressed to Damien D. Pearse; dpearse@med.miami.edu

Received 9 May 2015; Revised 21 October 2015; Accepted 9 November 2015

Academic Editor: Fakhrul Islam

Copyright (C) 2016 Jeffrey P. Datto et al. This is an open access article distributed under the Creative Commons Attribution License, which permits unrestricted use, distribution, and reproduction in any medium, provided the original work is properly cited.

\begin{abstract}
A possible cause of differences in recovery after spinal cord injury (SCI) is gender. The effect of gender on locomotor recovery following SCI, however, remains controversial and has produced conflicting results regarding gender's impact on outcome. A significant shortcoming of previous studies was small sample size. The current work tested what, if any, significant differences existed between genders after SCI with CatWalk Gait Analysis that uses an automated device to measure the foot placement and gait of animals as they voluntarily cross an illuminated glass runway. We hypothesized that, by employing larger sample sizes in a reproducible and clinically relevant contusive SCI paradigm, subtle distinctions in locomotor recovery between sexes, if they exist, would be elucidated. During 13 weeks of functional assessment after SCI, a number of CatWalk parameters, including swing, single stance, and stride length, were significantly affected by gender only as identified by use of ANCOVA analysis, considering age, weight, and baseline performance as covariates. We report here our findings for 197 parameters that were assessed before and after SCI. Evaluating differences in locomotor recovery between sexes after SCI could point to a gender-related advantage and provide novel directions for the development of future therapeutics.
\end{abstract}

\section{Introduction}

Spinal cord injury (SCI) produces motor and sensory deficits that impair functional performance [1]. Disability associated with traumatic SCI currently affects more than 250,000 chronically injured people in the US, $80.6 \%$ of whom are males [2]. Although treatments such as methylprednisolone are currently in use clinically, they are not completely effective in reversing the neurological dysfunction caused by SCI [35]. Thus, there is a dire need to find new treatments that can prevent such detrimental effects.
After the initial injury, secondary damage, which persists for weeks, occurs in response to the release of various cytotoxic molecules including proteases, metabolites, and oxidative species [6], in turn resulting in mitochondrial dysfunction $[7,8]$, the production of inflammatory cytokines, and immune cell activation $[9,10]$. Damage to the neuroarchitecture of the spinal cord also results in the liberation of toxic levels of neurotransmitters and calcium that induce neural cell death. The use of approaches to abrogate these mechanisms of injury is a major focus of SCI research for the development of new therapies. 
One key question that could potentially help in guiding the development of such treatments is whether gender plays a role in recovery after SCI. Previous studies have shown that the different sex hormones, testosterone, progesterone, and estrogen, can limit tissue damage and enhance recovery [11]. Though experimental studies have been undertaken to examine differences in cellular pathology after SCI among genders, few investigations have focused on the behavioral differences in recovery. Thus, the aim of this study was to determine whether gender-based differences existed in locomotor recovery after SCI.

The best way to address this question was to use an experimental model, a spinal cord contusion in rat, which could replicate the histopathological hallmarks of human injury and was amenable to the temporal evaluation of locomotor recovery with sensitive testing equipment. To assess locomotion in the rat, the CatWalk Gait Analysis Device, an automated gait analysis apparatus developed specifically for assessing rodent locomotion, was employed. The CatWalk Device tracks the foot placement and positioning of the rat's paws during conditioned walking along a runway and gathers information about various parameters of locomotion including stride length as well as limb couplings, paw print size, and print intensity [12]. In animal studies, gait analysis has been employed for the assessment of locomotive disturbances in models of ischemic stroke, SCI, and Parkinson's disease [13]. The CatWalk Gait Analysis Device was originally developed to improve the evaluation of locomotion following SCI by enhancing the detection of parameters associated with interlimb coordination [14]. The CatWalk Device, by assessing coordination after SCI through the measurement of the regularity index and phase relationships between each paw, is well suited for determining the effectiveness of therapies on recovery in commonly used experimental SCI models where this deficiency is a major component of the postinjury dysfunction. CatWalk analysis provides the ability to measure both static and dynamic changes in locomotion [15] and has also been employed to detect the presence of pain during walking [16]. Previous work has shown that the CatWalk Device can be used to detect changes in locomotor parameters immediately following and during the recovery phase of SCI [14].

The CatWalk Device has been employed in experimental SCI studies to both understand how specific injuries affect gait parameters and detect therapeutic effects of neuroprotective or reparative strategies. In the work by Pomeshchik and colleagues, measures of base of support, intensity of the paws, print length, width, and area, stand and swing speed and duration, maximum area and contact, stride length, and regularity index (RI) obtained from CatWalk analysis were employed to determine whether induced pluripotent stem cells enhanced recovery following SCI, demonstrating a significant difference in the regularity index between groups [17]. Forgione and coworkers employed CatWalk analysis to measure stride length, print area, print width, print length, swing speed, maximum area of contact, and intensity to evaluate the applicability of a rat cervical SCI paradigm for modeling functional deficits observed in human SCI. It was reported that all of the tested parameters decreased more in the hind limbs than in the forelimbs, except for stride length which had the opposite effect, and the work suggested that this experimental model was reflective of a human SCI [18]. CatWalk analysis has also been employed to evaluate the neuroprotective efficacy of gene therapy with growth factors on SCI recovery. Figley and colleagues presented an improvement in forelimb stride length, hind limb print area, print width, print length, and swing speed with the adenoviral delivery of vascular endothelial growth factor (AdV-ZFPVEGF) using CatWalk analysis [19]. CatWalk Gait Analysis has been employed to demonstrate either a beneficial effect or lack of effect of neurotrophin and chondroitinase engineered Schwann cells [20] or dissociated, predegenerated peripheral nerve transplants (dPDN) [21], respectively, after SCI. Recent studies have begun to investigate how alterations in cellular responses after SCI, through gene or transgenic manipulations, can affect locomotor recovery following SCI using CatWalk analysis [22, 23]. These studies demonstrate the wide utility and sensitivity of CatWalk Gait Analysis in both mechanistic and therapeutic studies of locomotor recovery after SCI, though the majority of these investigations have reported just a handful of the gait parameters measured by the CatWalk, largely stride length, print length, and base of support, in determining the degree of locomotor recovery. This is despite the CatWalk Device's ability to simultaneously measure over 150 gait parameters during rodent locomotion.

To date, whether gender has an effect on locomotion has not been assessed rigorously using CatWalk analysis, either inherently or during the recovery phase of SCI. Compared to prior work that has examined the effect of gender on outcome after SCI [24-29], the current study employed large sample sizes of male and female Fischer rats to address this question. Our hypothesis was that the sensitivity and reliability of automated CatWalk Gait Analysis would enable us to detect differences in locomotion between male and female rats if they existed. This work formed part of a larger investigation entitled "Female Rats Demonstrate Improved Locomotor Recovery and Greater Preservation of White and Grey Matter following Traumatic Spinal Cord Injury Compared to Males" which was recently published in the Journal of Neurotrauma [30]. The study employed a range of behavioral tests, including the Basso-Beattie-Bresnahan (BBB) score, BBB subscore, Tissue Volume Analysis, GridWalk, and CatWalk testing to determine whether there was a difference in histopathology or function attributed to gender following SCI. In the study we also discussed differences due to other factors such as age, weight, and activity. Histopathology was employed to examine differences in tissue sparing between males and females. However, this report only provided data on a very limited set of gait parameters measured by CatWalk analysis (Figure 1). The current work expands significantly this assessment by providing a comprehensive evaluation of all gait parameters across a large number of time points in determining the existence of a gender-related difference in post-SCI recovery using automated CatWalk Gait Analysis.

\section{Methodology}

For these studies, we employed both male $(n=26)$ and female $(n=33)$ Fischer rats $(N=59$; Harlan Laboratories, 


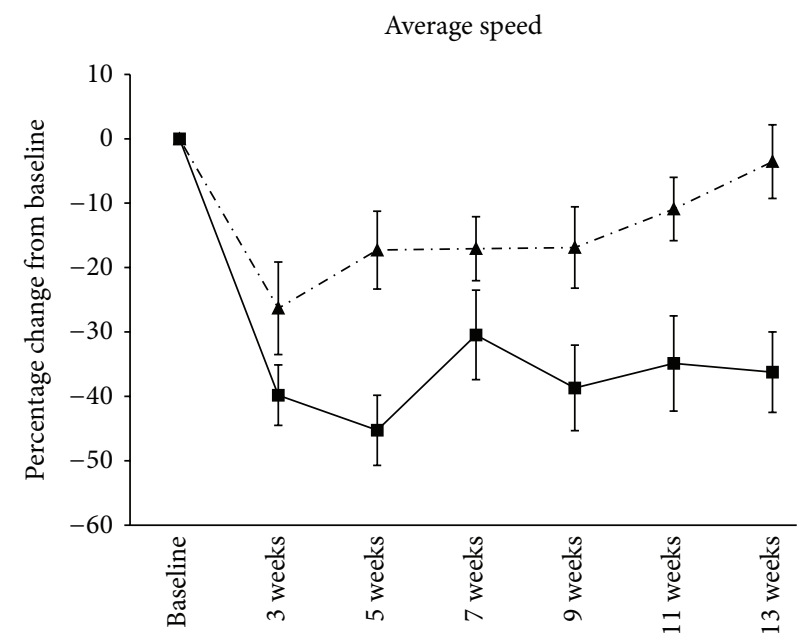

(a)

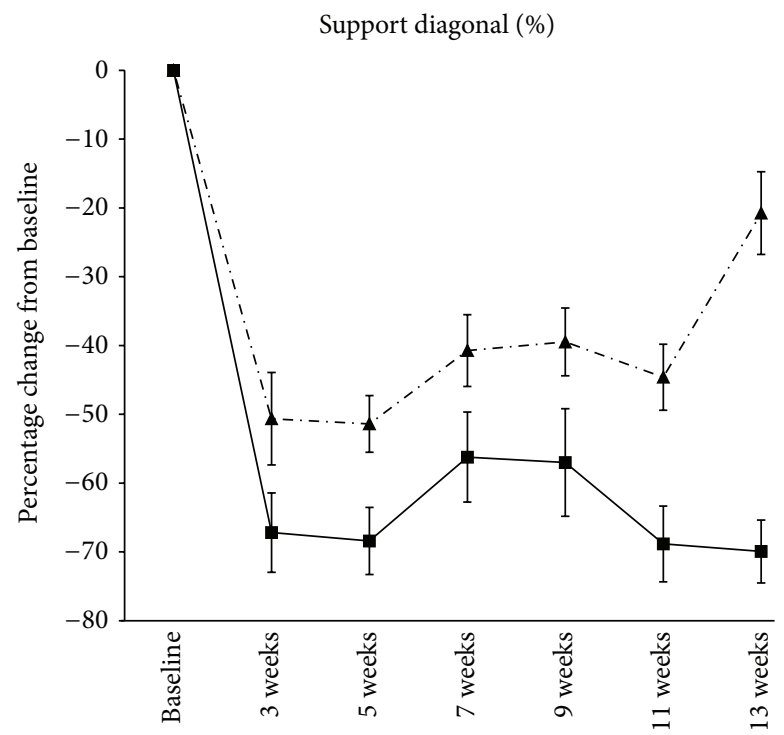

(c)

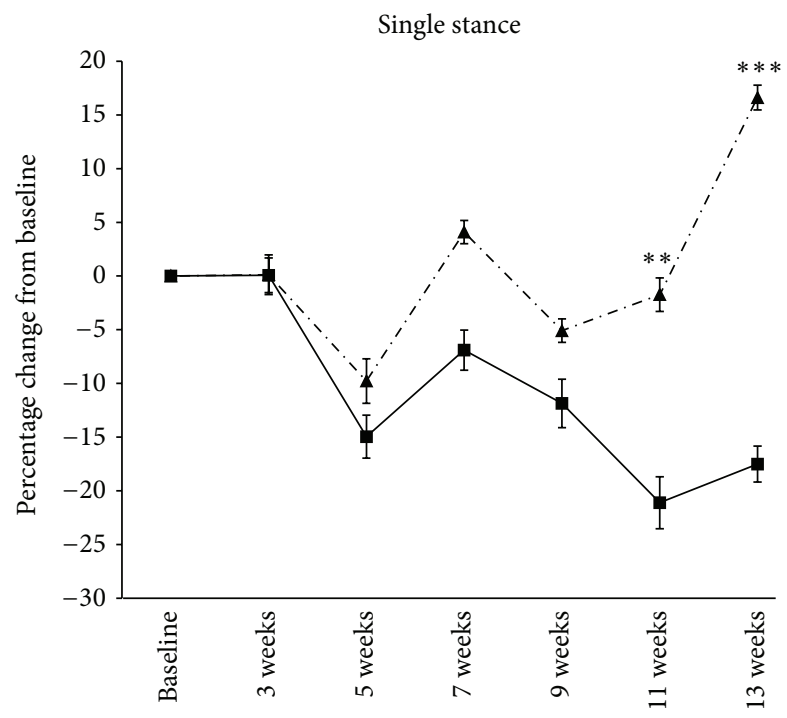

(e)

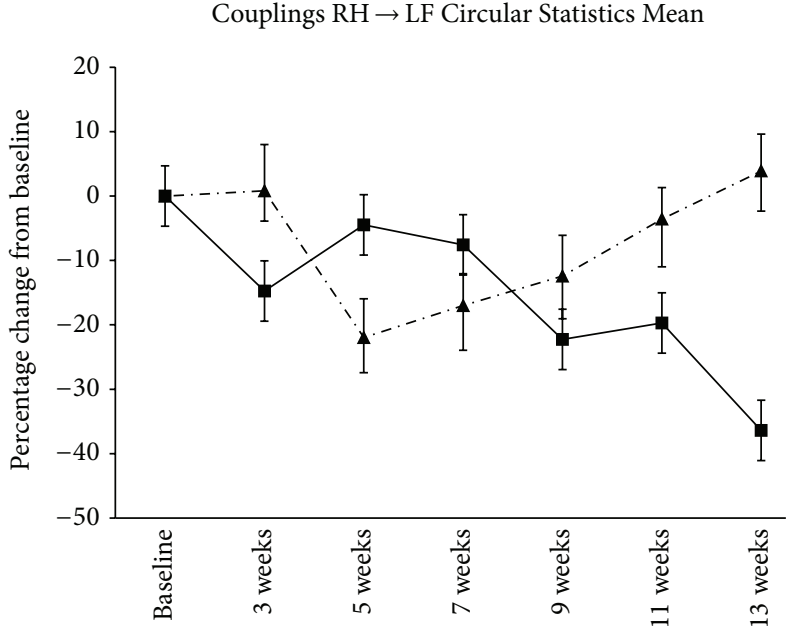

(b)

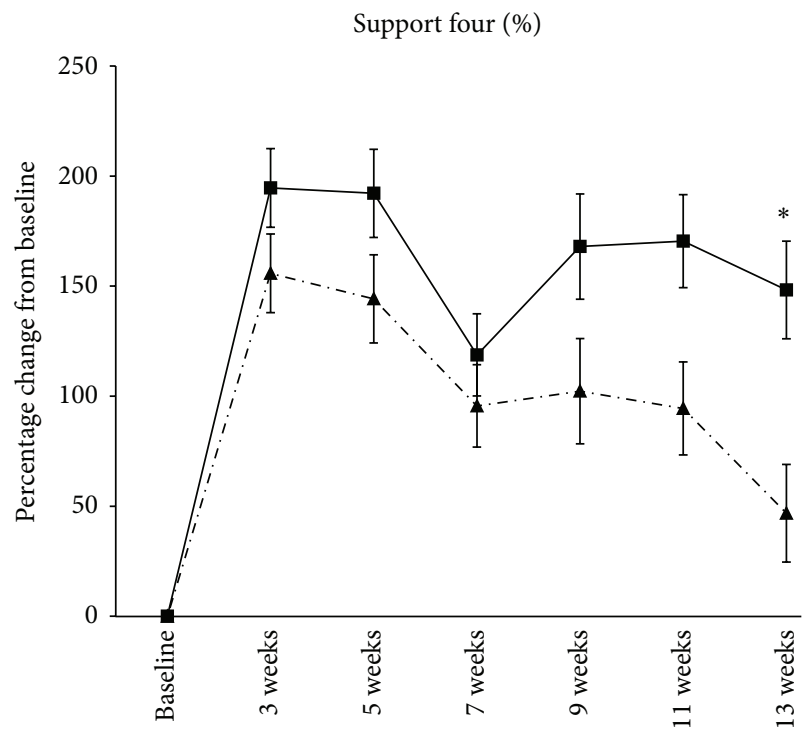

(d)

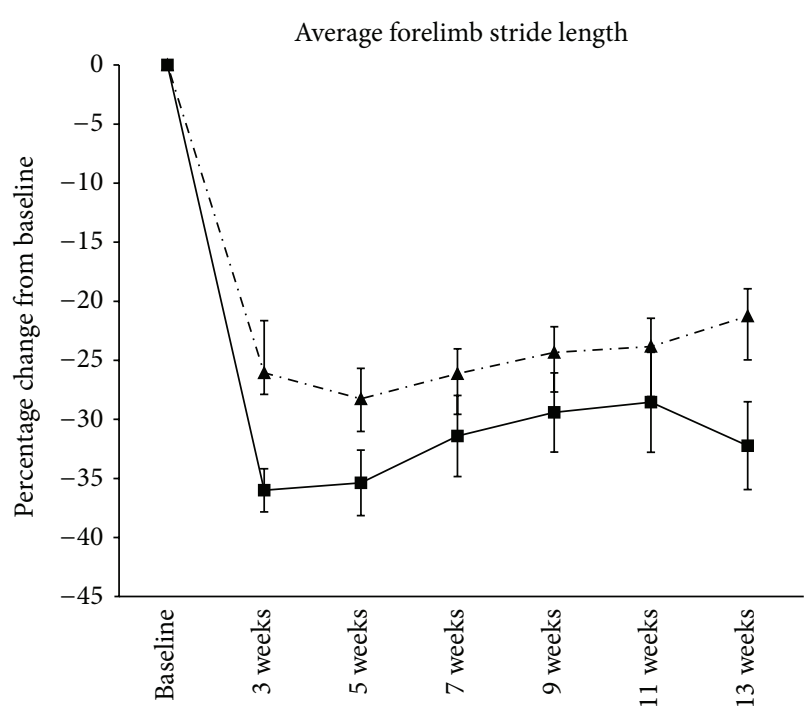

(f)

FIgure 1: Continued. 


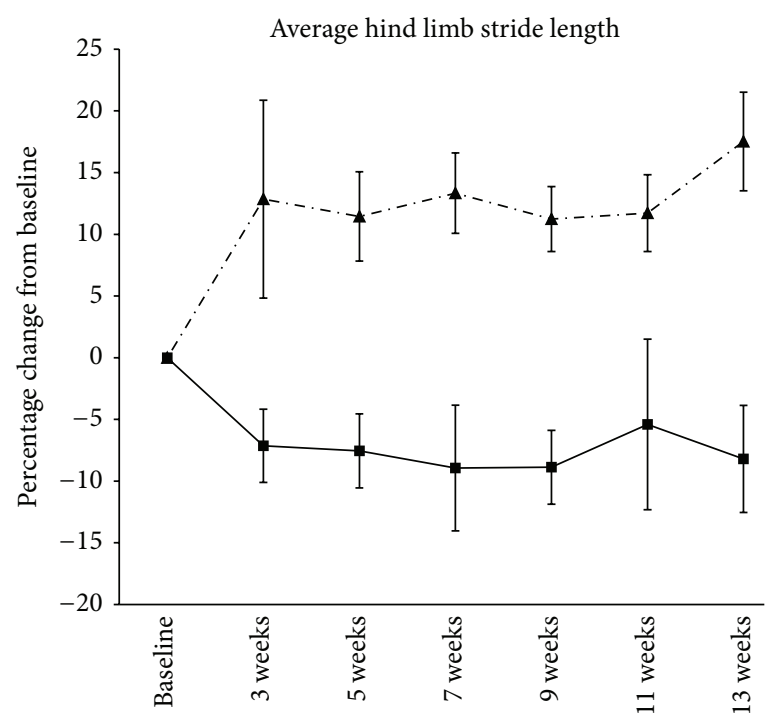

(g)

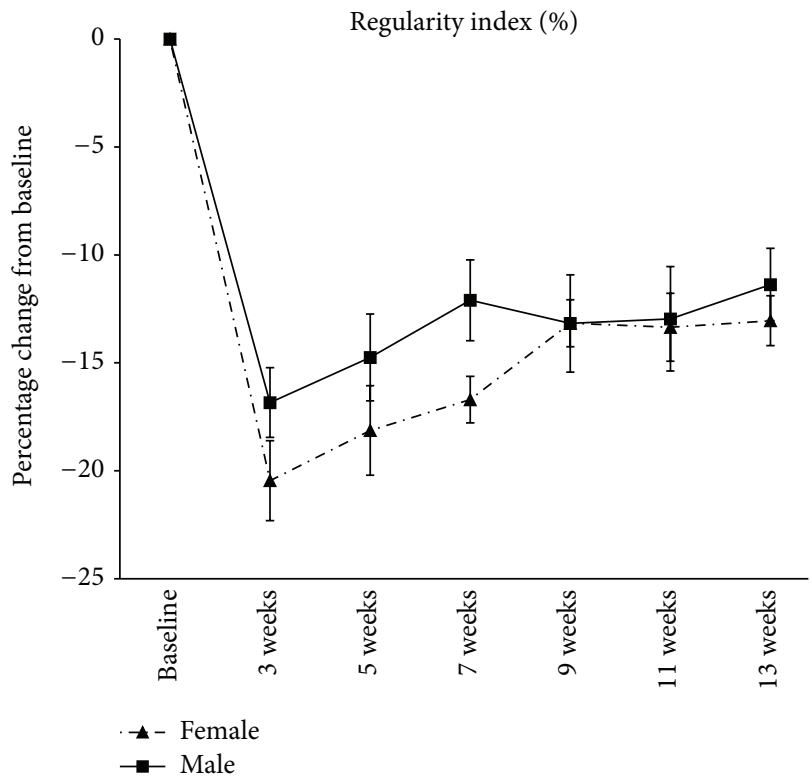

(i)

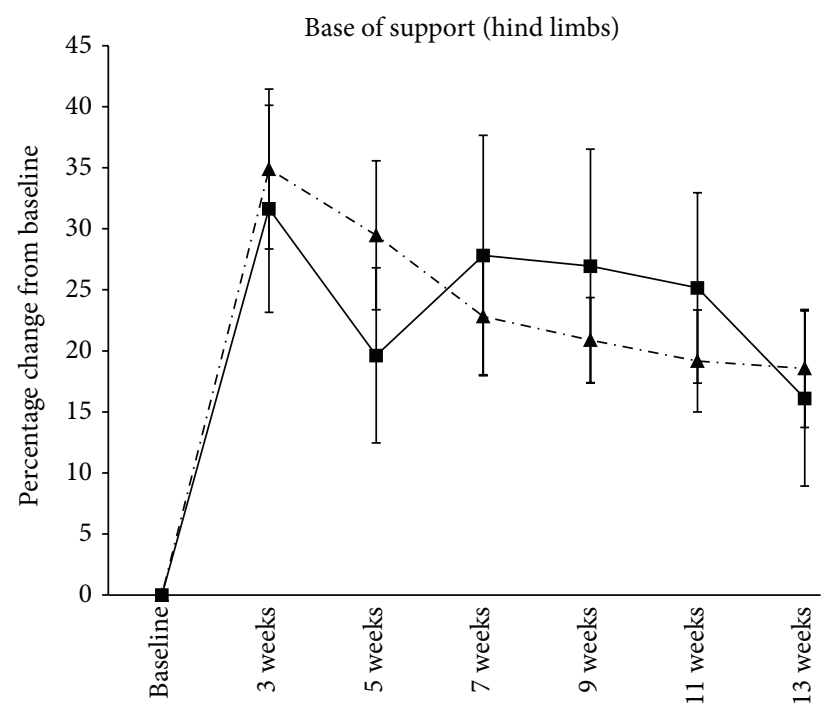

(h)

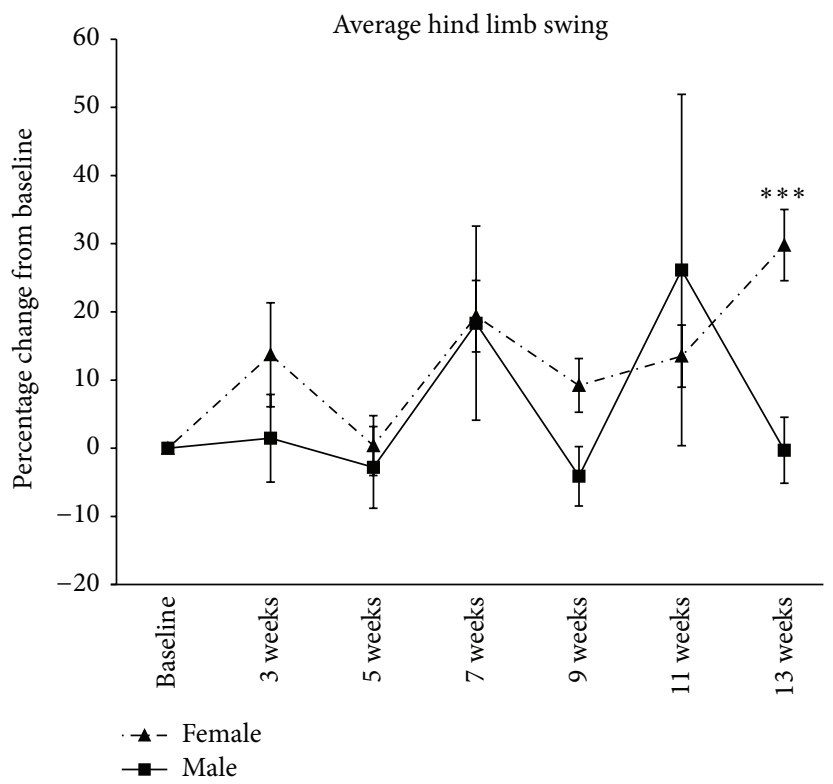

(j)

FIGURE 1: Female animals show less injury-induced deficit than males in hind limb stride, support diagonal, and single stance after SCI. Temporal analysis of a variety of CatWalk parameters (as calculated according to a percent error of gender-specific baseline values), speed (a), couplings of a diagonal paw pair (b), support diagonal (\%) (c), support four (\%) (d), single stance (e), forelimb stride length (f), hind limb stride length (g), hind limb base of support (h), regularity index (\%) (i), and hind limb swing (j), showed that females have less injury-induced deficit in stride length, support diagonal, and single stance than males. On other CatWalk parameters, similar post-SCI deficits in walking behavior were observed among genders. CatWalk analysis was performed before injury, three weeks after injury, and biweekly for 13 weeks after SCI. Weeks that showed a significant gender difference are shown by ${ }^{*} p<0.05,{ }^{* *} p<0.01$, or ${ }^{* * *} p<0.001$. This figure is from [30].

Inc.). The animals underwent acclimatization to the CatWalk experimental apparatus prior to the evaluation of their walking ability on the device. The animals were housed in pairs for the duration of the experiment in cages containing AlphaDri ${ }^{\circledR}$ bedding. All procedures were performed in accordance with NIH guidelines and the Guide for the Care and Use of Animals. These protocols were approved by the University of Miami Miller School of Medicine Institutional Animal Care and Use Committee (IACUC). The animals were weighed prior to and then periodically throughout the study. At the time of injury, the mean age and weight for males were 14.22 weeks and 260.36 grams and for females, 18.02 weeks and 193.14 grams.

Animals prior to surgical procedures were first anesthetized using a mixture of $2 \%$ isoflurane and $30 \%$ oxygen. Corneal and hind limb withdrawal reflexes were used to monitor the level of anesthesia. Once sufficient anesthesia was obtained, the posterior of the animals was shaved and 
aseptically prepared with chlorhexidine (Phoenix Pharmaceutical Inc., St. Joseph, MO). The eyes of the animals received the application of Lacrilube ophthalmic ointment (Allergan Pharmaceuticals, Irvine, CA) to prevent drying. The animals were placed upon a homoeothermic blanket system (Harvard Apparatus Ltd., Kent, UK) during surgery. The blanket was used to maintain body temperature at $37 \pm 0.5^{\circ} \mathrm{C}$, as measured by rectal probe.

The animals underwent experimental SCI using a MASCIS impactor, which provides the application of a reproducible contusive injury with a weight drop [31]. To expose the spinal cord prior to SCI induction, a laminectomy was performed at thoracic T8. The spinous processes at T6 and T12 were fixed with clamps to keep the animal stable during the impact by supporting the spinal column. The dorsal surface of the spinal cord then received SCI by dropping a $10.0 \mathrm{~g}$ rod from a height of $12.5 \mathrm{~mm}$ using the MASCIS impactor. To ensure the consistency of injuries among animals, the following exclusion parameters were used for the impacts: height or velocity errors $<7 \%$ and the compression distance within the range of 1.25 to $1.75 \mathrm{~mm}$. When using these exclusion criteria, a total of two males and four females were excluded at the time of SCI. A further two males were excluded after SCI due to the following complications: one bladder rupture and one preendpoint death. Following SCI, the animals received postoperative suturing of the muscles layers after which the skin was closed with metal wound clips.

Upon completion of SCI, the animals received postoperative recovery consisting of their initial placement in warmed cages that were localized upon thermoregulated heating pads. The animal's cages allowed easy access to water and food. The antibiotic Gentamicin ( $5 \mathrm{mg} / \mathrm{kg}$, intramuscular; Abbott Laboratories, North Chicago, IL) was provided in the initial postoperative care period and then daily for seven days. The analgesic Buprenex $(0.3 \mathrm{mg} / \mathrm{kg}$, subcutaneous; Reckitt Benckiser, Richmond, VA) was administered after surgery and then daily for two days. To ensure adequate hydration, Lactated Ringer's solution (5 cc, subcutaneous) was provided twice a day for seven days or longer as required. Until bladder function returned voluntarily, animals received manual bladder expression using the Crede method.

The walking patterns of the animals during conditioned locomotion along a runway were acquired and analyzed using the CatWalk Device (Noldus Information Technology Inc., Leesburg, VA) [32]. The CatWalk Device captures the location of the four paws during locomotion through a camera placed underneath the walkway, which is made of glass and illuminated by light. Following acclimatization, baseline performance was measured for the animals before injury. A measurable run was identified by the ability of the animals to take three or more consecutive steps without stopping while crossing the walkway, and from these runs, average values were obtained for analysis. The CatWalk software (ver. 10.1) was employed to label paw prints by adjusting the intensity threshold and autoclassifying the prints. Any labelling errors were manually corrected. The beginning of the run was determined when all four paws were down. The end of the run was designated as the last step before the animal went offscreen. All steps in between these two points were detected.
For baseline and two-week intervals up to the endpoint at 13 weeks (3, 5, 7, 9, 11, and 13 weeks), 197 different parameters were analyzed. The parameters with significant differences are presented as data for baseline, 3 weeks after injury, and 13 weeks after injury in tables for this dataset.

\section{Dataset Description}

The dataset associated with this Dataset Paper consists of 3 items which are described as follows.

Dataset Item 1 (Table). Results of ANCOVA, with age and weight as covariates, performed on the CatWalk data obtained at baseline from the animals, prior to SCI induction. Fifty-eight of the parameters revealed a significant difference $(p<0.05)$ between males and females. Of these parameters, 27 were intensity measures for each of the four paws including maximum intensity, mean intensity, maximum contact maximum intensity, maximum intensity at the mean, minimum intensity, and maximum intensity at the 15 most intense pixels. The differences show that the paw prints of female animals exhibited a higher intensity than those of males. Many of the other gait parameters found to be significant between genders were based upon assessments of stand, including average stand for hind paws, average stand index, and stand for the right front, right hind, and left front paws. This indicates that the female animals maintained their paws for a longer duration on the glass walkway than the males, which matches the larger values obtained for paw intensity levels. The initial and terminal dual stance were significant for right front, left front, and right hind paws in accordance also with stand. On the other hand, many speed parameters such as body speed, average speed, and swing speed were significant, showing that the males were faster than females in crossing the runway (Table 1).

$\begin{array}{ll}\text { Column 1: } & \text { Time Point } \\ \text { Column 2: } & \text { Gender } \\ \text { Column 3: } & \text { Run Duration Mean (s) } \\ \vdots & \\ \text { Column 197: } & \text { Left Front Print Area Mean }\left(\mathrm{cm}^{2}\right) \\ \text { Column 198: } & \text { Left Hind Maximum Contact Area Mean } \\ & \left(\mathrm{cm}^{2}\right)\end{array}$

Dataset Item 2 (Table). Results of ANCOVA performed at three weeks after SCI with age, weight, and baseline as covariates. Forty-seven parameters were found to be significant, $p<$ 0.05 , between genders. Of these parameters, 27 were associated with the intensity of the footprint of each paw including mean intensity of the 15 most intense pixels, maximum intensity, mean intensity, minimum intensity, maximum contact maximum intensity, and maximum contact mean intensity. Maximum intensity at contact (\%) was only significant for the hind limbs. Thus, females placed their paws with more force per unit area than males. In addition, females had higher 
TABLE 1: Baseline values.

\begin{tabular}{|c|c|c|c|c|c|c|}
\hline \multirow{2}{*}{ Parameters } & \multicolumn{2}{|c|}{ Females } & \multicolumn{3}{|c|}{ Males } & \multirow{2}{*}{$\begin{array}{c}\text { Bonferroni } \\
p\end{array}$} \\
\hline & Mean & SEM & Mean & SEM & $p$ & \\
\hline Left Front Maximum Contact Maximum Intensity Mean & 222.87 & 5.38 & 156.87 & 7.72 & 0.000 & 0.000 \\
\hline Left Front Maximum Intensity Mean & 227.41 & 5.34 & 162.39 & 7.67 & 0.000 & 0.000 \\
\hline Right Front Maximum Contact Maximum Intensity Mean & 221.63 & 5.38 & 159.72 & 7.71 & 0.000 & 0.000 \\
\hline Right Front Maximum Intensity Mean & 225.85 & 5.37 & 164.97 & 7.71 & 0.000 & 0.000 \\
\hline Right Front Mean Intensity of the 15 Most Intense Pixels Mean & 209.17 & 6.88 & 137.10 & 9.71 & 0.000 & 0.000 \\
\hline Left Front Mean Intensity of the 15 Most Intense Pixels Mean & 208.21 & 6.81 & 136.71 & 9.64 & 0.000 & 0.000 \\
\hline Right Front Maximum Contact Mean Intensity Mean & 140.04 & 5.26 & 85.73 & 7.63 & 0.000 & 0.000 \\
\hline Right Front Mean Intensity Mean & 143.84 & 5.35 & 88.59 & 7.78 & 0.000 & 0.000 \\
\hline Left Front Mean Intensity Mean & 143.95 & 5.31 & 89.85 & 7.73 & 0.000 & 0.000 \\
\hline Left Front Maximum Contact Mean Intensity Mean & 140.30 & 5.28 & 86.80 & 7.67 & 0.000 & 0.000 \\
\hline Right Hind Maximum Intensity Mean & 225.38 & 5.62 & 172.34 & 8.12 & 0.000 & 0.000 \\
\hline Right Hind Mean Intensity of the 15 Most Intense Pixels Mean & 214.99 & 6.85 & 152.64 & 9.72 & 0.000 & 0.000 \\
\hline Left Hind Maximum Contact Mean Intensity Mean & 139.71 & 5.50 & 88.06 & 7.94 & 0.000 & 0.000 \\
\hline Right Hind Maximum Intensity At Mean (\%) & 74.93 & 2.96 & 49.02 & 4.17 & 0.000 & 0.000 \\
\hline Left Hind Mean Intensity Mean & 142.99 & 5.44 & 93.56 & 7.89 & 0.000 & 0.000 \\
\hline Right Hind Maximum Contact Maximum Intensity Mean & 217.85 & 5.77 & 166.63 & 8.30 & 0.000 & 0.000 \\
\hline Left Hind Maximum Intensity Mean & 222.29 & 5.71 & 171.38 & 8.23 & 0.000 & 0.000 \\
\hline Right Hind Mean Intensity Mean & 143.38 & 5.59 & 94.54 & 8.14 & 0.000 & 0.000 \\
\hline Left Front Maximum Intensity At Mean (\%) & 40.44 & 2.44 & 59.76 & 3.40 & 0.000 & 0.000 \\
\hline Right Hind Maximum Contact Mean Intensity Mean & 139.57 & 5.69 & 90.76 & 8.24 & 0.000 & 0.000 \\
\hline Left Hind Maximum Contact Maximum Intensity Mean & 214.64 & 6.18 & 164.01 & 8.83 & 0.000 & 0.000 \\
\hline Couplings Left Front to Right Front Circular Statistics Mean & 44.70 & 1.21 & 53.90 & 1.67 & 0.000 & 0.000 \\
\hline Left Hind Mean Intensity of the 15 Most Intense Pixels Mean & 210.26 & 7.29 & 154.74 & 10.27 & 0.000 & 0.000 \\
\hline Right Hind Stand Index Mean & -2.12 & 0.27 & -4.04 & 0.38 & 0.001 & 0.006 \\
\hline Left Hind Minimum Intensity Mean & 74.29 & 3.72 & 45.88 & 5.36 & 0.001 & 0.006 \\
\hline Left Hind Body Speed Mean $\left(\mathrm{cm} \mathrm{s}^{-1}\right)$ & 15.92 & 1.14 & 23.81 & 1.60 & 0.001 & 0.006 \\
\hline Right Hind Step Cycle Mean (s) & 0.50 & 0.02 & 0.33 & 0.03 & 0.001 & 0.006 \\
\hline Left Front Minimum Intensity Mean & 74.16 & 3.75 & 46.83 & 5.40 & 0.001 & 0.006 \\
\hline Right Front Minimum Intensity Mean & 73.54 & 3.75 & 46.22 & 5.42 & 0.001 & 0.006 \\
\hline Left Front Body Speed Mean $\left(\mathrm{cm} \mathrm{s}^{-1}\right)$ & 16.18 & 1.17 & 23.99 & 1.63 & 0.001 & 0.006 \\
\hline Support Diagonal (\%) & 18.32 & 1.86 & 29.45 & 2.48 & 0.001 & 0.006 \\
\hline Right Hind Body Speed Mean $\left(\mathrm{cm} \mathrm{s}^{-1}\right)$ & 16.30 & 1.12 & 23.62 & 1.56 & 0.001 & 0.006 \\
\hline Phase Dispersions Left Front to Right Front Circular Statistics Mean & 46.28 & 1.27 & 54.46 & 1.76 & 0.001 & 0.006 \\
\hline Right Hind Minimum Intensity Mean & 73.87 & 3.90 & 46.43 & 5.63 & 0.002 & 0.012 \\
\hline Left Hind Maximum Intensity At Mean (\%) & 71.22 & 2.96 & 52.46 & 4.17 & 0.003 & 0.018 \\
\hline Other Statistics Average Speed Mean & 17.37 & 1.14 & 24.40 & 1.59 & 0.003 & 0.018 \\
\hline Run Average Speed Mean $\left(\mathrm{cm} \mathrm{s}^{-1}\right)$ & 12.68 & 1.27 & 20.04 & 1.74 & 0.003 & 0.018 \\
\hline Right Front Body Speed Mean $\left(\mathrm{cm} \mathrm{s}^{-1}\right)$ & 16.39 & 1.10 & 22.88 & 1.55 & 0.005 & 0.03 \\
\hline Other Statistics Cadence & 9.75 & 0.44 & 12.31 & 0.62 & 0.006 & 0.036 \\
\hline Average Stand Index Hind Paws & -2.25 & 0.23 & -3.59 & 0.33 & 0.006 & 0.036 \\
\hline Right Hind Initial Dual Stance Mean (s) & 0.12 & 0.01 & 0.05 & 0.02 & 0.006 & 0.036 \\
\hline Average Step Cycle Hind Paws & 0.48 & 0.02 & 0.35 & 0.03 & 0.008 & 0.048 \\
\hline Right Hind Stand Mean (s) & 0.34 & 0.02 & 0.23 & 0.03 & 0.008 & 0.048 \\
\hline Right Front Initial Dual Stance Mean (s) & 0.11 & 0.01 & 0.06 & 0.01 & 0.009 & 0.054 \\
\hline Right Front Step Cycle Mean (s) & 0.47 & 0.02 & 0.38 & 0.03 & 0.017 & 0.102 \\
\hline Left Front Terminal Dual Stance Mean (s) & 0.12 & 0.01 & 0.07 & 0.01 & 0.017 & 0.102 \\
\hline Average Swing Speed Hind Paws & 76.83 & 2.89 & 91.18 & 4.07 & 0.018 & 0.108 \\
\hline Couplings Right Hind to Left Front Circular Statistics Mean & 83.63 & 1.26 & 90.59 & 1.88 & 0.019 & 0.114 \\
\hline
\end{tabular}


TABLE 1: Continued.

\begin{tabular}{|c|c|c|c|c|c|c|}
\hline \multirow{2}{*}{ Parameters } & \multicolumn{2}{|c|}{ Females } & \multicolumn{3}{|c|}{ Males } & \multirow{2}{*}{$\begin{array}{c}\text { Bonferroni } \\
p\end{array}$} \\
\hline & Mean & SEM & Mean & SEM & $p$ & \\
\hline Couplings Left Hind to Right Front Mean & 77.87 & 2.75 & 90.72 & 3.86 & 0.025 & 0.15 \\
\hline Right Front Stand Mean (s) & 0.33 & 0.02 & 0.25 & 0.02 & 0.026 & 0.156 \\
\hline Left Front Swing Speed Mean $\left(\mathrm{cm} \mathrm{s}^{-1}\right)$ & 70.85 & 3.03 & 84.56 & 4.22 & 0.027 & 0.162 \\
\hline Right Hind Terminal Dual Stance Mean (s) & 0.14 & 0.01 & 0.08 & 0.02 & 0.032 & 0.192 \\
\hline Left Front Stand Mean (s) & 0.32 & 0.01 & 0.25 & 0.02 & 0.034 & 0.204 \\
\hline Left Front Step Cycle Mean (s) & 0.45 & 0.02 & 0.38 & 0.02 & 0.037 & 0.222 \\
\hline Average Stand Hind Paws & 0.33 & 0.02 & 0.25 & 0.03 & 0.037 & 0.222 \\
\hline Right Hind Swing Speed Mean $\left(\mathrm{cm} \mathrm{s}^{-1}\right)$ & 75.27 & 3.45 & 90.95 & 4.95 & 0.037 & 0.222 \\
\hline Phase Dispersions Left Front to Right Front Mean & 37.31 & 2.21 & 44.89 & 2.87 & 0.049 & 0.294 \\
\hline Left Front Initial Dual Stance Mean (s) & 0.10 & 0.01 & 0.07 & 0.01 & 0.050 & 0.300 \\
\hline
\end{tabular}

The data is organized with the parameters with the smallest $p$ value at the top of the table.

Bold font indicates parameters in which males have significantly higher values than females.

swing and higher swing speed than males indicating that they may have better balance control during locomotion than males after SCI at this time point and were generating more force in stepping, causing their hind paws to be in the air longer. On the other hand, males had significantly higher body speeds than females for each of the paws (Table 2). Increased body speeds with the hind paws having less time in the air would indicate that the naturally stronger males are compensating more with their noninjured upper body strength in crossing due to greater paw deficits.

\section{Column 1: Time Point \\ Column 2: Gender \\ Column 3: Run Duration Mean (s)
Column 197: Left Front Print Area Mean $\left(\mathrm{cm}^{2}\right)$
Column 198: Left Hind Maximum Contact Area Mean $\left(\mathrm{cm}^{2}\right)$ \\ Column 199: Left Hind Print Area Mean $\left(\mathrm{cm}^{2}\right)$}

Dataset Item 3 (Table). Results of ANCOVA performed at 13 weeks after injury with age, weight, and baseline as covariates. At this time point, there were 28 parameters that showed a significant difference between genders. Females exhibited significantly higher scores in hind limb swing, single stance, stride length, and also support lateral and support diagonal. These are all indicators of greater hind limb motor function and coordination. While males were continuing to move faster, they were doing so by increased reaching of the forepaws as seen in print positions and increased weight distribution and force to the forepaws as seen by the ratio of intensity of hind paws to forepaws (1.05, females; 0.97 , males). This compensation was also seen by significant differences between genders in couplings, which is a measurement of time between the placements of two paws in a step cycle, and duty cycle, which indicated that male rats were spending more time during a step cycle standing on the ground versus being able to generate the necessary force to push off the ground and have their paws in the air as long as the females (Table 3).

\author{
Column 1: Time Point \\ Column 2: Gender \\ Column 3: Run Duration Mean (s) \\ Column 197: Left Front Print Area Mean $\left(\mathrm{cm}^{2}\right)$ \\ Column 198: Left Hind Maximum Contact Area Mean \\ $\left(\mathrm{cm}^{2}\right)$ \\ Column 199: Left Hind Print Area Mean $\left(\mathrm{cm}^{2}\right)$
}

\section{Concluding Remarks}

Prior to this study, it was unclear whether a significant variance in functional recovery existed following SCI between males and females. Through the use of large group numbers and a detailed examination of locomotor performance with CatWalk Gait Analysis, our results show a significant difference in functional recovery between male and female rats that have undergone thoracic contusive SCI at each of the weeks in which function was examined after injury. Significant differences in locomotor recovery, favoring females, were detected as early as three weeks following SCI and remained significant at study endpoint, 13 weeks after SCI.

Another novel finding in this study was the significant difference in gait at baseline between male and female naïve rats on parameters such as base of support, couplings, paw size, intensity of paw prints, and average speed (Table 1). This is the first study to report such gender differences in CatWalk performance in naïve rats. A possible explanation for the increased intensity of paw prints of females over males is the fact that males have larger paws, and the amount of pressure exerted over a given force is less $(P=F / A)$. This can be seen in 27 out of 58 significant parameters that were intensity-related measures (Table 1). This finding for naïve 
TABLE 2: Week three post-SCI values.

\begin{tabular}{|c|c|c|c|c|c|c|}
\hline \multirow{2}{*}{ Parameters } & \multicolumn{2}{|c|}{ Females } & \multicolumn{3}{|c|}{ Males } & \multirow{2}{*}{$\begin{array}{c}\text { Bonferroni } \\
p\end{array}$} \\
\hline & Mean & SEM & Mean & SEM & $p$ & \\
\hline Left Hind Minimum Intensity & 84.11 & 4.21 & 33.96 & 6.58 & 0.000 & 0.000 \\
\hline Left Hind Maximum Contact Mean Intensity & 156.87 & 6.54 & 80.19 & 10.38 & 0.000 & 0.000 \\
\hline Right Front Minimum Intensity & 81.69 & 4.38 & 32.04 & 6.79 & 0.000 & 0.000 \\
\hline Left Front Minimum Intensity & 82.31 & 4.36 & 32.99 & 6.78 & 0.000 & 0.000 \\
\hline Right Hind Minimum Intensity & 83.89 & 4.72 & 35.25 & 7.34 & 0.000 & 0.000 \\
\hline Right Front Maximum Contact Mean Intensity & 159.74 & 6.56 & 92.27 & 10.51 & 0.000 & 0.000 \\
\hline Left Hind Mean Intensity & 161.98 & 7.06 & 90.83 & 11.21 & 0.000 & 0.000 \\
\hline Right Hind Maximum Contact Mean Intensity & 157.96 & 7.33 & 85.90 & 11.57 & 0.000 & 0.000 \\
\hline Right Front Mean Intensity & 161.43 & 6.78 & 94.67 & 10.90 & 0.000 & 0.001 \\
\hline Left Front Maximum Contact Mean Intensity & 158.39 & 6.96 & 91.86 & 11.09 & 0.000 & 0.001 \\
\hline Left Hind Mean Intensity of the 15 Most Intense Pixels & 223.19 & 8.07 & 154.05 & 12.17 & 0.000 & 0.001 \\
\hline Right Hind Mean Intensity of the 15 Most Intense Pixels & 230.75 & 8.49 & 158.56 & 12.88 & 0.000 & 0.001 \\
\hline Left Front Mean Intensity & 160.70 & 7.23 & 94.80 & 11.55 & 0.000 & 0.001 \\
\hline Left Front Mean Intensity of the 15 Most Intense Pixels & 224.71 & 7.93 & 156.09 & 12.32 & 0.000 & 0.001 \\
\hline Left Hind Maximum Contact Maximum Intensity & 223.55 & 7.50 & 159.71 & 11.52 & 0.000 & 0.002 \\
\hline Left Hind Maximum Intensity & 235.40 & 7.48 & 172.28 & 11.61 & 0.000 & 0.002 \\
\hline Right Front Mean Intensity of the 15 Most Intense Pixels & 224.29 & 7.29 & 161.90 & 11.59 & 0.000 & 0.003 \\
\hline Right Hind Mean Intensity & 165.05 & 8.06 & 97.67 & 12.71 & 0.001 & 0.004 \\
\hline Right Hind Maximum Intensity & 240.98 & 8.06 & 176.90 & 12.43 & 0.001 & 0.004 \\
\hline Right Hind Maximum Intensity At (\%) & 72.50 & 3.28 & 47.53 & 4.89 & 0.001 & 0.004 \\
\hline Right Hind Maximum Contact Maximum Intensity & 224.68 & 7.80 & 167.09 & 12.05 & 0.002 & 0.009 \\
\hline Left Front Maximum Intensity & 228.86 & 7.24 & 178.31 & 11.45 & 0.004 & 0.023 \\
\hline Right Hind Step Cycle (s) & 0.71 & 0.04 & 0.50 & 0.05 & 0.005 & 0.028 \\
\hline Right Front Maximum Intensity & 228.44 & 6.76 & 182.15 & 10.79 & 0.005 & 0.030 \\
\hline Left Hind Body Speed $\left(\mathrm{cm} \mathrm{s}^{-1}\right)$ & 9.99 & 1.33 & 17.47 & 1.91 & 0.007 & 0.039 \\
\hline Left Front Maximum Contact Maximum Intensity & 221.89 & 7.19 & 177.29 & 11.40 & 0.010 & 0.062 \\
\hline Right Front Maximum Contact Maximum Intensity & 222.29 & 6.60 & 181.36 & 10.54 & 0.011 & 0.066 \\
\hline Right Hind Body Speed Variation (\%) & 38.95 & 3.29 & 20.18 & 5.05 & 0.012 & 0.071 \\
\hline Right Front Body Speed Variation (\%) & 39.94 & 3.16 & 21.89 & 4.87 & 0.012 & 0.073 \\
\hline Right Hind Body Speed $\left(\mathrm{cm} \mathrm{s}^{-1}\right)$ & 10.19 & 1.20 & 16.35 & 1.72 & 0.013 & 0.079 \\
\hline Maximum Run Variation (\%) & 115.93 & 9.18 & 71.58 & 13.12 & 0.016 & 0.093 \\
\hline Average Step Cycle Hind Paws & 0.68 & 0.04 & 0.51 & 0.05 & 0.020 & 0.119 \\
\hline Right Hind Single Stance (s) & 0.11 & 0.01 & 0.08 & 0.01 & 0.020 & 0.122 \\
\hline Average Swing Speed Hind Paws & 79.48 & 4.43 & 99.66 & 6.24 & 0.022 & 0.131 \\
\hline Left Front Body Speed $\left(\mathrm{cm} \mathrm{s}^{-1}\right)$ & 10.64 & 1.26 & 16.63 & 1.82 & 0.023 & 0.135 \\
\hline Left Front Body Speed Variation (\%) & 39.16 & 2.96 & 23.95 & 4.57 & 0.024 & 0.143 \\
\hline Left Hind Body Speed Variation (\%) & 39.04 & 3.84 & 21.04 & 5.67 & 0.027 & 0.160 \\
\hline Right Front Body Speed $\left(\mathrm{cm} \mathrm{s}^{-1}\right)$ & 10.86 & 1.24 & 16.47 & 1.79 & 0.030 & 0.183 \\
\hline Other Statistics Cadence & 8.76 & 0.50 & 10.97 & 0.72 & 0.031 & 0.187 \\
\hline Left Hind Maximum Intensity At (\%) & 65.51 & 3.38 & 50.02 & 4.95 & 0.034 & 0.204 \\
\hline Left Hind Swing (s) & 0.15 & 0.01 & 0.11 & 0.01 & 0.039 & 0.233 \\
\hline Ratio Intensity Hind Paws to Forepaws Maximum & 1.00 & 0.02 & 0.93 & 0.03 & 0.041 & 0.244 \\
\hline Couplings Left Front to Right Front Mean & 39.56 & 1.31 & 44.57 & 1.82 & 0.043 & 0.260 \\
\hline Average Hind Paw Swing & 0.15 & 0.01 & 0.11 & 0.01 & 0.049 & 0.293 \\
\hline Average Swing Hind Limb & 0.15 & 0.01 & 0.11 & 0.01 & 0.049 & 0.293 \\
\hline Step Sequence RA (\%) & 7.27 & 3.78 & 21.41 & 5.28 & 0.050 & 0.301 \\
\hline
\end{tabular}

The data is organized with the parameters with the smallest $p$ value at the top of the table. 
TABLE 3: Week thirteen post-SCI values.

\begin{tabular}{|c|c|c|c|c|c|c|}
\hline \multirow{2}{*}{ Parameters } & \multicolumn{2}{|c|}{ Females } & \multicolumn{3}{|c|}{ Males } & \multirow{2}{*}{$\begin{array}{c}\text { Bonferroni } \\
p\end{array}$} \\
\hline & Mean & SEM & Mean & SEM & $p$ & \\
\hline Average Single Stance Hind Limb & 0.13 & 0.01 & 0.07 & 0.01 & 0.000 & 0.000 \\
\hline Average Hind Paw Swing & 0.17 & 0.01 & 0.10 & 0.01 & 0.000 & 0.000 \\
\hline Average Swing Hind Limb & 0.17 & 0.01 & 0.10 & 0.01 & 0.000 & 0.000 \\
\hline Right Hind Single Stance (s) & 0.13 & 0.01 & 0.07 & 0.01 & 0.000 & 0.002 \\
\hline Left Hind Swing (s) & 0.17 & 0.01 & 0.11 & 0.01 & 0.001 & 0.004 \\
\hline Support Four (\%) & 21.65 & 2.35 & 39.81 & 3.61 & 0.001 & 0.005 \\
\hline Average Duty Cycle Hind Paws & 64.67 & 1.66 & 76.32 & 2.46 & 0.001 & 0.005 \\
\hline Couplings Left Front to Right Front Circular Statistics Mean & 45.19 & 1.29 & 53.88 & 1.93 & 0.002 & 0.011 \\
\hline Average Swing Speed Hind Paws & 71.52 & 3.59 & 95.23 & 5.38 & 0.002 & 0.015 \\
\hline Phase Dispersions Left Front to Right Front Circular Statistics Mean & 45.64 & 1.22 & 53.72 & 1.85 & 0.003 & 0.017 \\
\hline Left Hind Single Stance (s) & 0.12 & 0.01 & 0.08 & 0.01 & 0.004 & 0.021 \\
\hline Right Hind Swing (s) & 0.16 & 0.01 & 0.11 & 0.01 & 0.004 & 0.024 \\
\hline Left Front Swing (s) & 0.10 & 0.00 & 0.08 & 0.01 & 0.004 & 0.027 \\
\hline Right Hind Duty Cycle (\%) & 64.79 & 2.05 & 77.21 & 3.07 & 0.005 & 0.031 \\
\hline Support Diagonal (\%) & 16.99 & 1.35 & 8.90 & 2.01 & 0.005 & 0.033 \\
\hline Print Positions Left Paws $(\mathrm{cm})$ & 5.99 & 0.54 & 9.19 & 0.81 & 0.006 & 0.039 \\
\hline Support Lateral (\%) & 10.99 & 1.16 & 4.77 & 1.71 & 0.010 & 0.060 \\
\hline Left Front Stand Index & -6.49 & 0.39 & -4.37 & 0.58 & 0.012 & 0.069 \\
\hline Left Hind Duty Cycle (\%) & 64.76 & 1.96 & 75.09 & 2.90 & 0.012 & 0.072 \\
\hline Right Hind Stride Length Mean $(\mathrm{cm})$ & 11.11 & 0.45 & 8.78 & 0.66 & 0.014 & 0.081 \\
\hline Right Front Duty Cycle (\%) & 71.34 & 1.20 & 77.83 & 1.84 & 0.016 & 0.099 \\
\hline Ratio Intensity Hind Paws to Forepaws Mean & 1.05 & 0.02 & 0.97 & 0.02 & 0.016 & 0.099 \\
\hline Average Stride Length Hind Limbs & 11.13 & 0.45 & 8.93 & 0.66 & 0.019 & 0.114 \\
\hline Left Hind Stride Length $(\mathrm{cm})$ & 11.23 & 0.48 & 8.92 & 0.71 & 0.022 & 0.130 \\
\hline Right Hind Swing Speed $\left(\mathrm{cm} \mathrm{s}^{-1}\right)$ & 72.20 & 4.42 & 94.86 & 6.82 & 0.026 & 0.157 \\
\hline Couplings Left Front to Right Front Mean & 38.84 & 0.87 & 42.98 & 1.31 & 0.029 & 0.175 \\
\hline Print Positions Right Paws (cm) & 5.84 & 0.50 & 8.24 & 0.76 & 0.030 & 0.182 \\
\hline Left Front Duty Cycle (\%) & 70.98 & 1.37 & 77.06 & 2.08 & 0.045 & 0.272 \\
\hline
\end{tabular}

The data is organized with the parameters with the smallest $p$ value at the top of the table.

uninjured animals is interesting and further studies should be conducted regarding how these disparities could affect the interpretation of observations made after injury.

After SCI, a significant difference between genders in intensity measures persisted. In addition, there were significant differences in hind limb single stance, stride length, maximum contact area, and swing which showed that females had better locomotor recovery than males. This data indicates that females were taking longer steps with better individual hind limb weight support. Furthermore, males had significantly higher print positions which was indicative of increased reaching of their forepaws to provide forward propulsion. With this increased reaching, males also had an increased weight support shift towards their forepaws from their hind paws as seen in the significant difference in the ratio of the intensity of hind paws to forepaws. This gait difference was detected in coupling measurements, which were also significantly different between genders after injury.

In sum, this dataset provides detailed support for the conclusion that a detectable gender difference in functional recovery, favoring females, does exist following a clinically relevant SCI in the rat.

\section{Dataset Availability}

The dataset associated with this Dataset Paper is dedicated to the public domain using the CCO waiver and is available at http://dx.doi.org/10.1155/2016/6276348/dataset.

\section{Competing Interests}

The authors declare no competing interests existing in the material in the paper.

\section{Acknowledgments}

The authors thank Denise Koivisto, Eva Juarez, Alex Basagoitia, Ronald Zambrano, Miguel Martinez, and Ramon German for help with animal care; Paulo Diaz for surgical assistance; Lindsay Connor for data analysis; and Leah 
Colucci and Hanna Mathers for data organization and quality assurance review of the CatWalk data. Vivien Chen and Jackie Yang are thanked for proofreading this paper. This research was supported by the Department of Defense Congressionally Directed Medical Research Programs (SCIRP) Award no. W81XWH-10-1-0793, The Miami Project to Cure Paralysis, The Buoniconti Fund, and The John M. and Jocelyn H.K. Watkins Distinguished Chair in Cell Therapies (D.D.P.).

\section{References}

[1] A. D. Kloos, L. C. Fisher, M. R. Detloff, D. L. Hassenzahl, and D. M. Basso, "Stepwise motor and all-or-none sensory recovery is associated with nonlinear sparing after incremental spinal cord injury in rats," Experimental Neurology, vol. 191, no. 2, pp. 251265, 2005.

[2] M. J. Devivo, "Epidemiology of traumatic spinal cord injury: trends and future implications," Spinal Cord, vol. 50, no. 5, pp. 365-372, 2012.

[3] M. L. Sipski and D. D. Pearse, "Methylprednisolone and other confounders to spinal cord injury clinical trials," Nature Clinical Practice Neurology, vol. 2, no. 8, pp. 402-403, 2006.

[4] A. G. Rabchevsky, S. P. Patel, and J. E. Springer, "Pharmacological interventions for spinal cord injury: where do we stand? How might we step forward?" Pharmacology and Therapeutics, vol. 132, no. 1, pp. 15-29, 2011.

[5] B. K. Kwon, E. Okon, J. Hillyer et al., "A systematic review of non-invasive pharmacologic neuroprotective treatments for acute spinal cord injury," Journal of Neurotrauma, vol. 28, no. 8, pp. 1545-1588, 2011.

[6] F. Antunes and E. Cadenas, "Cellular titration of apoptosis with steady state concentrations of $\mathrm{H}_{2} \mathrm{O}_{2}$ : submicromolar levels of $\mathrm{H}_{2} \mathrm{O}_{2}$ induce apoptosis through fenton chemistry independent of the cellular thiol state," Free Radical Biology and Medicine, vol. 30, no. 9, pp. 1008-1018, 2001.

[7] S. Barut, A. Canbolat, T. Bilge, Y. Aydin, B. C.Cokneşeli, and U. Kaya, "Lipid peroxidation in experimental spinal cord injury: time-level relationship," Neurosurgical Review, vol. 16, no. 1, pp. 53-59, 1993.

[8] D. D. Pearse, F. C. Pereira, A. E. Marcillo et al., "cAMP and Schwann cells promote axonal growth and functional recovery after spinal cord injury," Nature Medicine, vol. 10, no. 6, pp. 610$616,2004$.

[9] L. I. Benowitz and P. G. Popovich, "Inflammation and axon regeneration," Current Opinion in Neurology, vol. 24, no. 6, pp. 577-583, 2011.

[10] S. L. Carlson, M. E. Parrish, J. E. Springer, K. Doty, and L. Dossett, "Acute inflammatory response in spinal cord following impact injury," Experimental Neurology, vol. 151, no. 1, pp. 77-88, 1998.

[11] S. Elkabes and A. B. Nicot, "Sex steroids and neuroprotection in spinal cord injury: a review of preclinical investigations," Experimental neurology, vol. 259, pp. 28-37, 2014.

[12] F. F. Hamers, I. Devaux, J. Alix, and A. Nardone, "HIV/AIDS in Europe: trends and EU-wide priorities," Eurosurveillance, vol. 11, no. 11, Article ID E061123.1, 2006.

[13] Y. Liu, L. J. Ao, G. Lu et al., "Quantitative gait analysis of longterm locomotion deficits in classical unilateral striatal intracerebral hemorrhage rat model," Behavioural Brain Research, vol. 257, pp. 166-177, 2013.
[14] F. P. T. Hamers, G. C. Koopmans, and E. A. J. Joosten, "CatWalkassisted gait analysis in the assessment of spinal cord injury," Journal of Neurotrauma, vol. 23, no. 3-4, pp. 537-548, 2006.

[15] R. Deumens, R. J. P. Jaken, M. A. E. Marcus, and E. A. J. Joosten, "The CatWalk gait analysis in assessment of both dynamic and static gait changes after adult rat sciatic nerve resection," Journal of Neuroscience Methods, vol. 164, no. 1, pp. 120-130, 2007.

[16] C.-Y. Chiang, M.-L. Sheu, F.-C. Cheng et al., "Comprehensive analysis of neurobehavior associated with histomorphological alterations in a chronic constrictive nerve injury model through use of the CatWalk XT system: laboratory investigation," Journal of Neurosurgery, vol. 120, no. 1, pp. 250-262, 2014.

[17] Y. Pomeshchik, K. A. Puttonen, I. Kidin et al., “Transplanted human induced pluripotent stem cell-derived neural progenitor cells do not promote functional recovery of pharmacologically immunosuppressed mice with contusion spinal cord injury," Cell Transplantation, vol. 24, no. 9, pp. 1799-1812, 2015.

[18] N. Forgione, S. K. Karadimas, W. D. Foltz, K. Satkunendrarajah, A. Lip, and M. G. Fehlings, "Bilateral contusion-compression model of incomplete traumatic cervical spinal cord injury," Journal of Neurotrauma, vol. 31, no. 21, pp. 1776-1788, 2014.

[19] S. A. Figley, Y. Liu, S. K. Karadimas et al., "Delayed administration of a bio-engineered zinc-finger VEGF-A gene therapy is neuroprotective and attenuates allodynia following traumatic spinal cord injury," PLoS ONE, vol. 9, no. 5, Article ID e96137, 2014.

[20] H. Kanno, Y. Pressman, A. Moody et al., "Combination of engineered Schwann cell grafts to secrete neurotrophin and chondroitinase promotes axonal regeneration and locomotion after spinal cord injury," The Journal of Neuroscience, vol. 34, no. 5, pp. 1838-1855, 2014.

[21] C. E. Hill, D. M. Brodak, and M. Bartlett Bunge, "Dissociated predegenerated peripheral nerve transplants for spinal cord injury repair: a comprehensive assessment of their effects on regeneration and functional recovery compared to schwann cell transplants," Journal of Neurotrauma, vol. 29, no. 12, pp. 22262243, 2012.

[22] H. A. Petrosyan, A. S. Hunanyan, V. Alessi, L. Schnell, J. Levine, and V. L. Arvanian, "Neutralization of inhibitory molecule NG2 improves synaptic transmission, retrograde transport, and locomotor function after spinal cord injury in adult rats," The Journal of Neuroscience, vol. 33, no. 9, pp. 4032-4043, 2013.

[23] N. Cho, D. H. Nguyen, K. Satkunendrarajah, D. R. Branch, and M. G. Fehlings, "Evaluating the role of IL-11, a novel cytokine in the IL- 6 family, in a mouse model of spinal cord injury," Journal of Neuroinflammation, vol. 9, article 134, 2012.

[24] M. Farooque, Z. Suo, P. M. Arnold et al., "Gender-related differences in recovery of locomotor function after spinal cord injury in mice," Spinal Cord, vol. 44, no. 3, pp. 182-187, 2006.

[25] K. R. Swartz, D. B. Fee, K. M. Joy et al., "Gender differences in spinal cord injury are not estrogen-dependent," Journal of Neurotrauma, vol. 24, no. 3, pp. 473-480, 2007.

[26] R. V. Ung, N. P. Lapointe, C. Tremblay, A. Larouche, and P. A. Guertin, "Spontaneous recovery of hindlimb movement in completely spinal cord transected mice: a comparison of assessment methods and conditions," Spinal Cord, vol. 45, no. 5, pp. 367-379, 2007.

[27] E. Hauben, T. Mizrahi, E. Agranov, and M. Schwartz, "Sexual dimorphism in the spontaneous recovery from spinal cord injury: a gender gap in beneficial autoimmunity?" European Journal of Neuroscience, vol. 16, no. 9, pp. 1731-1740, 2002. 
[28] D. B. Fee, K. R. Swartz, K. M. Joy, K. N. Roberts, N. N. Scheff, and S. W. Scheff, "Effects of progesterone on experimental spinal cord injury," Brain Research, vol. 1137, no. 1, pp. 146-152, 2007.

[29] A. Singh, M. Murray, and J. D. Houle, "A training paradigm to enhance motor recovery in contused rats: effects of staircase training," Neurorehabilitation and Neural Repair, vol. 25, no. 1, pp. 24-34, 2011.

[30] J. P. Datto, J. C. Bastidas, N. L. Miller et al., "Female rats demonstrate improved locomotor recovery and greater preservation of white and gray matter after traumatic spinal cord injury compared to males," Journal of Neurotrauma, vol. 32, no. 15, pp.11461157, 2015.

[31] J. A. Gruner, "A monitored contusion model of spinal cord injury in the rat," Journal of Neurotrauma, vol. 9, no. 2, pp. 123128, 1992.

[32] F. P. T. Hamers, A. J. Lankhorst, T. J. Van Laar, W. B. Veldhuis, and W. H. Gispen, "Automated quantitative gait analysis during overground locomotion in the rat: its application to spinal cord contusion and transection injuries," Journal of Neurotrauma, vol. 18, no. 2, pp. 187-201, 2001. 

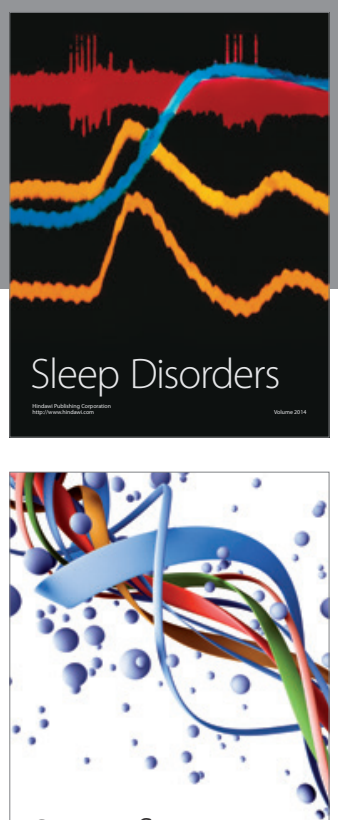

Scientifica
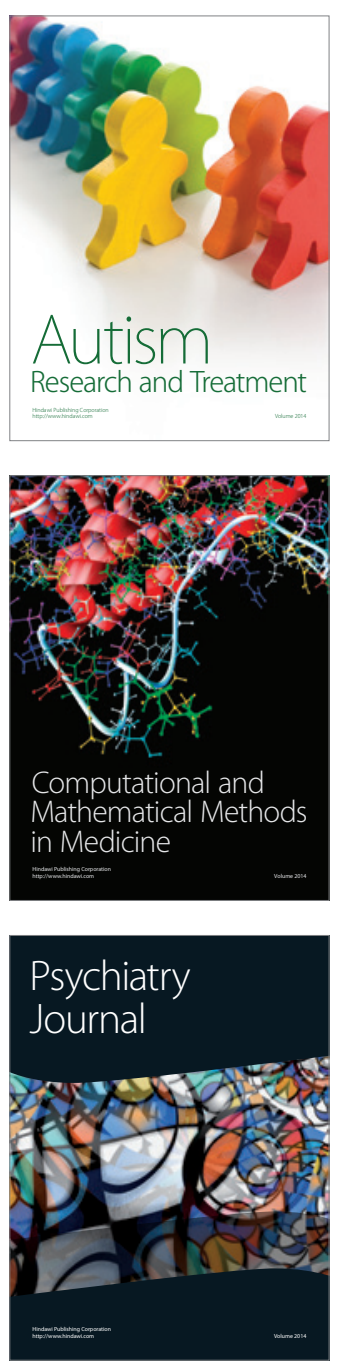
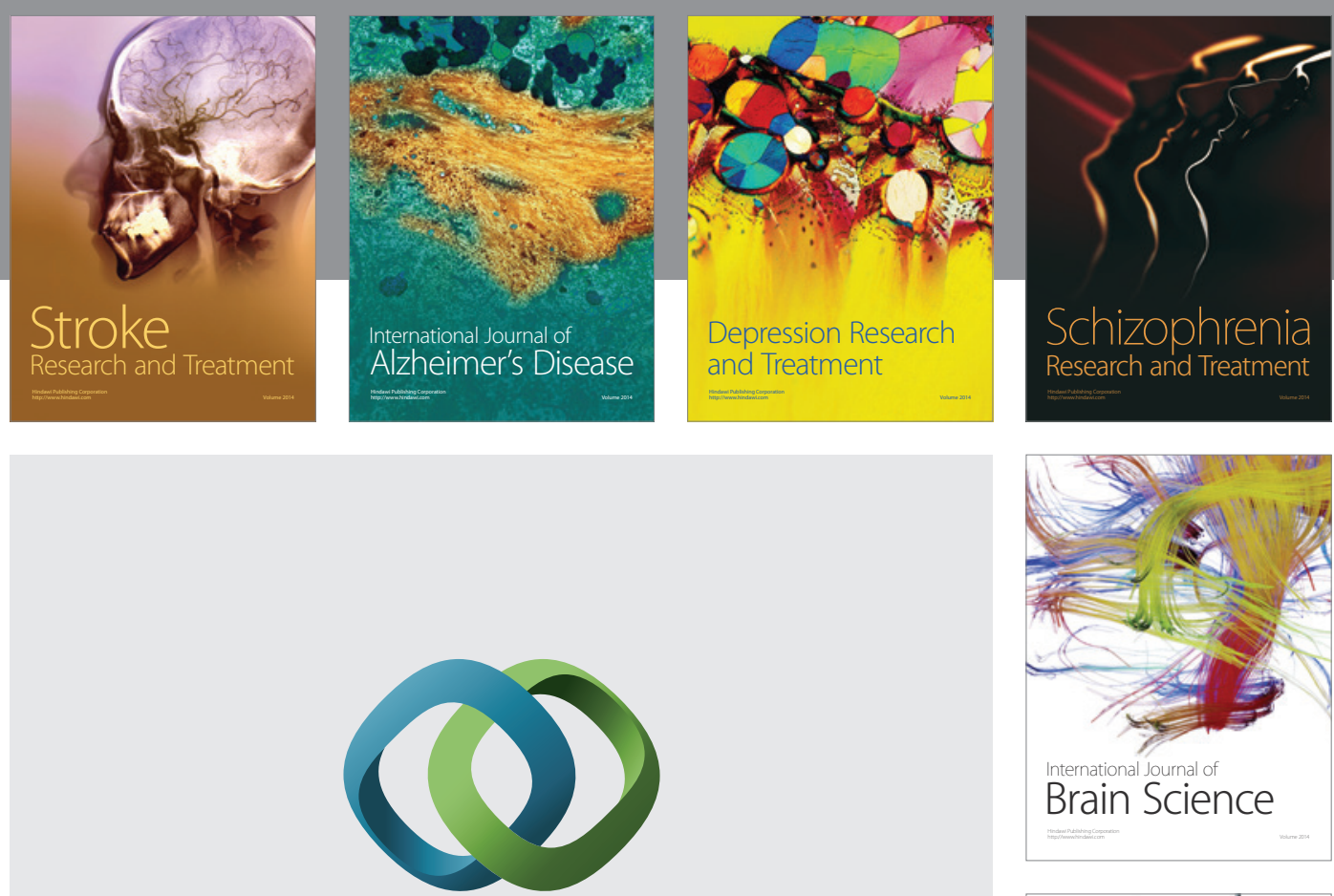

\section{Hindawi}

Submit your manuscripts at

http://www.hindawi.com
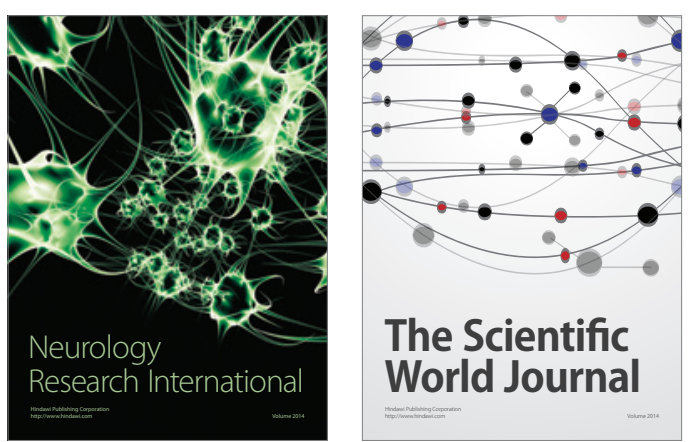

The Scientific World Journal

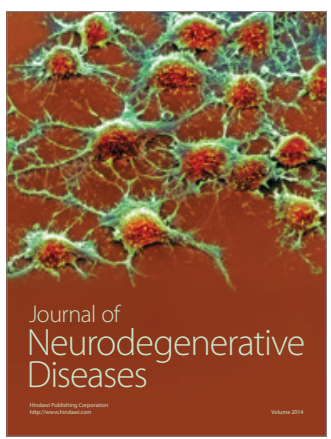

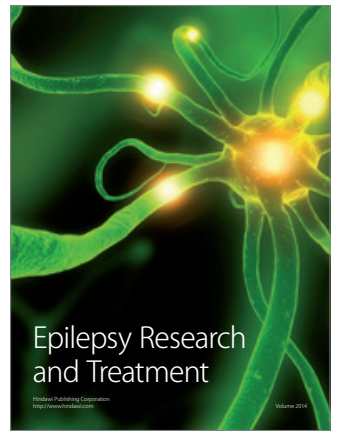

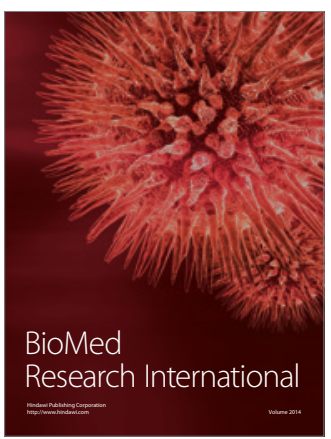

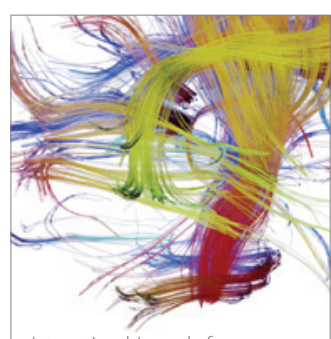

Brain Science

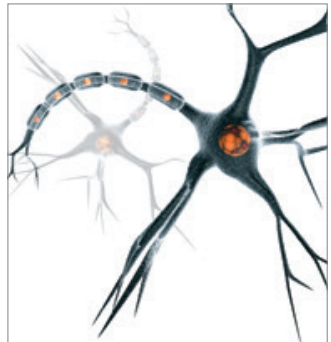

Neural Plasticity
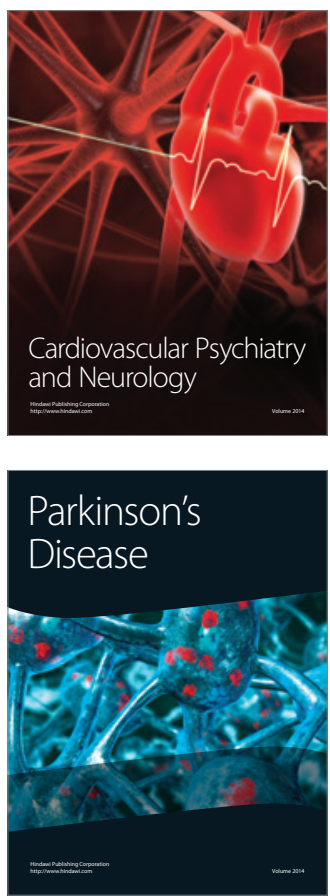